\title{
Prevalence and Socioeconomic Inequalities in
}

\section{Eight or More Antenatal Care Contacts in Ghana: Findings from 2019 Population-Based Data}

This article was published in the following Dove Press journal: International Journal of Women's Health

\author{
Michael Ekholuenetale' \\ Chimezie lgwegbe Nzoputam (iD) ${ }^{2}$ \\ Amadou Barrow iD ${ }^{3}$ \\ 'Department of Epidemiology and \\ Medical Statistics, Faculty of Public \\ Health, College of Medicine, University of \\ Ibadan, Ibadan, Nigeria; ${ }^{2}$ Department of \\ Community Health, Center of Excellence \\ in Reproductive Health Innovation \\ (CERHI), College of Medical Sciences, \\ University of Benin, Benin City, Nigeria; \\ ${ }^{3}$ Department of Public \& Environmental \\ Health, School of Medicine \& Allied \\ Health Sciences, University of the \\ Gambia, Kanifing, The Gambia
}

Background: For the prevention of complications and death during pregnancy, adequate antenatal care (ANC) contacts are important. To achieve optimal obstetric care, the latest ANC guidance recommends eight or more ANC contacts. The aim of this analysis is to investigate the prevalence and socio-economic differences of eight or more Ghanaian ANC contacts.

Methods: A total sample of 1404 women of reproductive age who had given birth after eight or more ANC contacts had been initiated, taking into account 9 months of gestation, was studied. The Ghana Malaria Indicator Survey of 2019 (GMIS) was used. In the univariate analysis, percentage was used. The curve and concentration index of Lorenz were used to assess socio-economic disparities for eight or more ANC contacts. Statistical significance was set at $5 \%$.

Results: The weighted prevalence of eight or more ANC contacts was $41.9 \%(95 \% \mathrm{CI}$ : $37.9-45.9 \%$ ). The prevalence of eight or more ANC contacts among the poorest, poorer, middle, richer and richest households was $34.0 \%, 36.1 \%, 35.8 \%, 42.4 \%$ and $59.6 \%$, respectively. Similarly, 33.0\%, 37.7\% and $42.6 \%$ prevalence of eight or more ANC contacts were estimated among women with no formal education, primary, secondary or higher, respectively. In addition, women from rich household had greater coverage of eight or more ANC contacts (Conc. Index $=0.089 ; \mathrm{SE}=0.019$ ) and educated women had greater coverage of eight or more ANC contacts in Ghana (Conc. Index=0.053; $\mathrm{SE}=0.017)($ all $\mathrm{p}<0.001)$.

Conclusion: Eight or more ANC contacts from the WHO in 2016 have yet to be fully institutionalized in Ghana. In order to increase access to the recommended prenatal care and for a healthy pregnancy experience, measures that resolve disparities in healthcare usage need to be prioritized for the country. Efforts should be made to expand the health insurance services available, as well as to enact policies that will increase free health care particularly among the poor and uneducated women.

Keywords: inequality, WHO, maternal health, women, 2016 ANC guideline

\section{Background}

The process of pregnancy and childbirth is among major events that take place in womanhood. The ability to conceive and give birth to a child brings much fulfilment to both the woman and her family. Albeit, there are many predisposing, enabling and need factors affecting healthcare during pregnancy including women's socioeconomic status. ${ }^{1}$ Inadequate healthcare utilization could have put subSaharan Africa (SSA) among the highest contributor to the global level of maternal mortality rates, resulting from complications during pregnancy and childbirth. ${ }^{2}$
Correspondence: Amadou Barrow Email abarrow@utg.edu.gm
International Journal of Women's Health 2021:13 349-360 
Though the causes of these deaths are often preventable through access and adequate antenatal care (ANC) services utilization, several resource-constrained countries have poor health care system and unable to prevent large number of these deaths. ${ }^{3}$

Access to health care services is disproportionately distributed among diverse socioeconomic groups in many SSA countries. ${ }^{1}$ Evidence-based studies reported that women and children from low socioeconomic class have less access to health care services and are plagued with the highest number of morbidity and mortality in the society when compared to those from the high socioeconomic class. $^{4-8}$ Socioeconomic inequality in healthcare use has often been observed in most developing countries, including African countries and have the most worrisome reports. ${ }^{9-12}$ The third and tenth Sustainable Development Goals (SDGs) are targeted to eliminate inequality "ensure healthy lives and promote well-being for all at all ages" and "reduce inequality within and among countries". ${ }^{13}$ To achieve this, particularly in resource-constrained settings, adequate and sustainable efforts are required to end several barriers that plague access to health care service utilization including socioeconomic inequality.

The World Health Organization (WHO) Universal Health Coverage (UHC) was brought to limelight to address inequality in access and use of healthcare services. ${ }^{8,14}$ This was geared towards enhancing maternal and child healthcare through the elimination of barriers that limit accessibility and affordability of services among the disadvantaged and vulnerable population. The UHC sorts to give healthcare access to the most-at-risk and disadvantaged populace. This was due to large evidence of socioeconomic inequality in the utilization of healthcare services. ${ }^{15}$ The need for ANC services is crucial to everyone as it presents the expectant mothers an opportunity to uptake proper care. Moreover, it helps in early detection of danger signs and health promotions. ${ }^{16}$

In 2016, WHO made a recommendation of eight ANC contacts, overriding the previous recommendation of a minimum of four ANC visits. ${ }^{1,16}$ Prior to the guideline for eight or more ANC contacts, reports showed that only $60 \%$ of women worldwide had at least four ANC visits, and only about $52 \%$ of women from SSA countries had at least four ANC visits with trained health care providers. ${ }^{17}$ The benefits of adequate ANC are numerous; including reduction in adverse pregnancy outcomes, promotion of women's health, reduction in perinatal and newborn morbidity and mortality amongst others. ${ }^{18-20}$ Also, it has been found to encourage the use of skilled birth attendance as well as promote postnatal care utilization. ${ }^{1,21-26}$

It seems that Ghana has started to see some change in maternal health. Ghana's maternal mortality ratio (MMR) has decreased gradually in the past two decades. The country's maternal mortality ratio was calculated at 484 per 100,000 live births in $2000 ; 371$ per 100,000 live births in $2005 ; 339$ per 100,000 live births in 2010; 320 per 100,000 live births in 2015; and 308 per 100,000 live births in 2017 , being an overall reduction in MMR of $36 \%$ between 2000 and $2017 .^{3}$ This is lower than the estimates from many other African countries. ${ }^{3}$ This figure though seemingly low, still very high and needs to be reduced in line with the SDG-3; "by 2030 reduce the global maternal mortality ratio to less than 70 per 100,000 live births". ${ }^{13}$ Socioeconomic inequality in maternal health care utilization in Ghana is a major barrier to achieve the SDG3 , but can be brought to a barest minimum if financial barriers that exist in the health system is removed. ${ }^{27}$ Exempting the pregnant women from paying out-ofpocket could be a strategy to encourage adequate ANC contacts as well as reduction in socioeconomic inequalities as per healthcare use. ${ }^{28}$ Previous efforts to remove user-fee contributed to the initiation of National Health Insurance Scheme (NHIS), as a tool to eliminate barriers in accessing healthcare services in Ghana. The National Health Insurance Act (Act 650) scheme also has the aim of enhancing financial access, particularly among key population for optimal healthcare utilization. ${ }^{28}$ Over the years, the use of NHIS seems to promote maternal healthcare service utilization in Ghana, though there are still reports of out-ofpocket expenditures. ${ }^{27-30}$

Evidence-based studies have reported that socioeconomic status is a key determining factor in healthcare service utilization. For instance, the economic status of a woman or her family (wealth status), ${ }^{31,32}$ level of education of a woman, ${ }^{33}$ level of education of the husband as well as the woman's autonomy ${ }^{33-35}$ were significant factors in healthcare utilization, respectively. To the best of our knowledge, this study is the first of its kind to examine the prevalence and socioeconomic inequalities in the uptake of eight or more ANC contacts in Ghana, after the WHO recommendation for eight or more ANC contacts with trained health care provider was launched. 


\section{Methods}

\section{Data Extraction}

For this study, a total sample of 1404 women of reproductive age who had given birth following the criteria of eight or more ANC contacts was initiated by WHO, taking into account 9 months of gestation. The Ghana Malaria Indicator Survey (GMIS) 2019 was used. All reproductiveage women (15-49 years) who were either visitors or who lived permanently in the chosen households were eligible to be interviewed. The 2019 GMIS sample also includes key elements of maternal health data such as ANC contacts, although it was intended to provide estimates of key malaria indicators for the country and for each of the 10 administrative regions (Western, Central, Greater Accra, Volta, Eastern, Ashanti, Brong Ahafo, Northern, Upper East, and Upper West) as identified in the 2010 Population and Housing Census of Ghana. The sampling method used for the 2019 GMIS is the 2010 PHC framework carried out by the Ghana Statistical Service in Ghana (GSS). A full list of all census enumeration areas (EAs) created for the PHC is the frame. An EA is the smallest geographic region that can be easily surveyed during an enumeration exercise by an enumerator. Details on the EA area, type of residence (rural or urban), the estimated number of residential households and the estimated population are included in the sampling frame.

\section{Sampling Design}

In two separate steps, the 2019 GMIS sample was stratified and selected from the sampling frame. Each region was split into rural and urban areas, resulting in 20 sampling layers. In two steps, samples of EAs were selected separately in each stratum. Approximately 200 EAs (103 in rural areas and 97 in urban areas) were selected in the first level, with a probability proportional to EA size and in-depth, respectively. In all of the selected EAs, a household listing procedure was conducted from 24 June to 10 August 2019. A fixed number of 30 households were chosen from each cluster in the second stage of selection to make up a total sample size of 6000 households. Details of the sampling method have already been published. ${ }^{36}$

\section{Selection Criteria}

We included women who had given birth after WHO launched the guideline of eight or more ANC contacts, considering 9 months of gestation. ANC models with a minimum of eight contacts are recommended in the Guideline to minimize perinatal mortality and enhance the experience of women in treatment. ${ }^{16}$

\section{Variable Selection and Measurement Outcome}

Dichotomous measurements were taken of the frequency of ANC encounters with physicians, nurses and midwives. In order to derive this variable, the GMIS asked the question "Number of antenatal visits during pregnancy?" The answers to this question were classified as $<8$ or $\geq 8$ contacts. A review structure for the 2016 WHO ANC is provided in the WHO ANC guideline recommendations mapped to the eight suggested contacts. ${ }^{16,37,38}$

\section{Independent Variables}

In order to assess socioeconomic status in line with previous research, women's educational achievement and income quintiles were used. ${ }^{39-41}$ The achievement of women's education was classified as no formal education, primary, secondary or higher. The wealth indicator weights were determined using the principal component analysis (PCA) technique to assign the wealth indicator weights. Wealth indicator variable scores were allocated and standardized using household assets such as wall type, floor type, roof type, water supply, sanitation facilities, radio, electricity, television, refrigerator, cooking fuel, furniture, number of persons per room. The factor loadings and z-scores have then been determined. The indicator values were multiplied by the factor loadings for each household and summarized to generate the wealth index value of the household. To categorize the overall scores into wealth quintiles, the standardized z-score was used; poorest, poorer, middle, richest and richest. $^{42}$

Other explanatory variables include respondent age (year): 15-24, 25-34, 35+; residential status: urban, rural; religion: Christianity, Islam, traditional/no religion; timing to antenatal care booking: late (after 1st trimester), early (within 1st trimester); health insurance coverage: not covered, covered; household headship: male, female; preceding birth interval: first born, <2years, 2-3years, 4 +years; parity: 1-2, 3-4, 5+; region: Western, Central, Greater Accra, Volta, Eastern, Ashanti, Brong Ahafo, Northern, Upper East, Upper West; ethnicity: Akan, Ga/ Dangme, Ewe, Guan, Mole-Dagbani, Grusi, Gurma, Mande, Other. 


\section{Statistical Analysis}

For sampling design, the survey module ("svy") command was used. In univariate analysis, percentage was used. The Lorenz curve and concentration index for eight or more ANC contacts were used to analyze socio-economic disparities. When eight or more ANC contacts are higher among high socioeconomic classes, the concentration index value is positive. Conversely, when the concentration index value is negative, it indicates that among low socioeconomic classes, eight or more ANC contacts are higher. The explanatory variables for stratified analyses were used. The concentration index was used in eight or more ANC contacts to compute the contrast. ${ }^{43,44}$ Statistical significance was determined at $\mathrm{p}<0.05$. Stata version 14 (StataCorp., College Station, TX, USA) was used for data analysis.

\section{Ethical Consideration}

In the public domain, we used the secondary data available. The ICF Institutional Review Board and the Ghana Health Service Ethical Review Committee have approved the procedure for the 2019 GMIS. The advantages and risks of participating in the survey have been explained to participants. Prior to administration of the Household or Women's Questionnaire, informed consent was obtained directly from qualified respondents. Participation was voluntary in the survey. The names and identification numbers of the respondents were omitted from the final data sets.

\section{Results}

The weighted prevalence of eight or more ANC contacts was $41.9 \%$ (95\% CI: $37.9-45.9 \%)$. The prevalence of eight or more ANC contacts among the poorest, poorer, middle, richer and richest households was $34.0 \%, 36.1 \%$, $35.8 \%, 42.4 \%$ and $59.6 \%$, respectively. Similarly, 33.0\%, $37.7 \%$ and $42.6 \%$ prevalence of eight or more ANC contacts were estimated among women with no formal education, primary, secondary + , respectively. Overall, women aged $35+$, urban dweller, Christianity belief, initiated ANC contact within first trimester, covered by health insurance, primiparous, Western or Upper East region and Grusi ethnic background had the highest prevalence of eight or more ANC contacts, respectively. See Table 1 for the details.

Figures 1 and 2 show household wealth and women's education inequalities for eight or more ANC contacts in
Ghana. A higher degree of inequalities is confirmed by how far away the curves sag away from the line of equality. Figures 1 and 2 show that women from rich households and those educated had greater coverage of eight or more ANC contacts in Ghana as the line of equality sags below the diagonal line, respectively.

Table 2 shows results of household wealth and mothers' education inequalities for eight or more ANC contacts in Ghana. Overall, women from rich household had greater coverage of eight or more ANC contacts (Conc. Index $=0.089 ; \mathrm{SE}=0.019$ ) and educated women had greater coverage of eight or more ANC contacts in Ghana (Conc. Index $=0.053$; SE $=0.017$ ). See Table 2 for the details.

\section{Discussion}

This is the foremost study in Ghana to examine the socioeconomic inequalities in eight or more ANC contacts. Based on the WHO recommendations, a minimum number of eight ANC contacts should be made with a trained health care provider by the 40th gestation week. This was necessary as the minimum of four ANC visits earlier proposed or recommended was seen to be inadequate to enhance the survival of mothers and children alike, especially in developing countries. This new recommendation requires a woman to visit trained health care provider at least once in her first trimester, twice in her second trimester (weeks 20 and 26) and five times in her third and final trimester (weeks 30, 34, 36, 38 and 40, respectively). ${ }^{16,45}$

This study estimated a weighted $41.9 \%$ prevalence of eight or more ANC contacts among Ghanaian women of reproductive age. This prevalence is higher than the findings from previous studies from Nigeria $(17.4 \%)^{46}$ and Benin Republic (8.0\%). ${ }^{47}$ The higher prevalence of eight ANC or more contacts observed among Ghanaian women may be as a result of the improvement in maternal and child health seen in Ghana in recent years. ${ }^{48}$ It has been reported that since the policy that sought a complete removal of financial burden barriers from pregnant women who registered with the Ghanian NHIS, many rural women and those from poor and less privileged backgrounds could seek for maternal and child health care without barriers. ${ }^{49}$ A report showed that this policy has positively imparted the use of maternal health care in Ghana. ${ }^{49}$ Prior to implementation of the policy on maternal health care utilization, it was a norm that prenatal and postnatal mothers were required to pay out-of-pocket or 
Table I Distribution of Eight or More Antenatal Care Contacts Across Socioeconomic Status and by Women's Characteristics

\begin{tabular}{|c|c|c|c|c|c|c|c|c|c|c|}
\hline \multirow[t]{3}{*}{ Variable } & \multirow[t]{3}{*}{ n (\%) } & \multirow{3}{*}{$\begin{array}{l}\text { Eight or } \\
\text { More } \\
\text { ANC } \\
\text { Contacts, } \\
\%\end{array}$} & \multicolumn{8}{|c|}{ Eight or More Antenatal Care Contacts } \\
\hline & & & \multicolumn{5}{|c|}{ Household Wealth Quintile } & \multicolumn{3}{|c|}{ Mothers' Educational Attainment } \\
\hline & & & $\begin{array}{l}\text { Lowest } \\
\text { (Poorest) }\end{array}$ & $\begin{array}{l}\text { Second } \\
\text { Level }\end{array}$ & Middle & $\begin{array}{l}\text { Fourth } \\
\text { Level }\end{array}$ & $\begin{array}{l}\text { Highest } \\
\text { (Richest) }\end{array}$ & $\begin{array}{l}\text { No } \\
\text { Education }\end{array}$ & Primary & $\begin{array}{l}\text { Secondary } \\
\text { or Higher }\end{array}$ \\
\hline \multicolumn{11}{|l|}{ Age } \\
\hline $15-24$ & $435(31.0)$ & 33.8 & 34.9 & 27.9 & 35.6 & 31.5 & 51.7 & 26.3 & 33.0 & 35.6 \\
\hline $25-34$ & $670(47.7)$ & 40.0 & 28.8 & 38.5 & 34.6 & 47.2 & 62.6 & 30.3 & 35.5 & 46.1 \\
\hline $35+$ & $299(21.3)$ & 45.5 & 42.7 & 44.8 & 40.0 & 45.5 & 58.5 & 40.2 & 50.0 & 48.3 \\
\hline \multicolumn{11}{|c|}{ Residential status } \\
\hline Urban & $55 \mathrm{I}(39.3)$ & 43.4 & 32.7 & 43.6 & 40.7 & 48.1 & 64.3 & 29.6 & 42.6 & 46.6 \\
\hline Rural & $853(60.7)$ & 36.6 & 34.8 & 31.2 & 32.9 & 38.4 & 56.0 & 34.1 & 35.3 & 38.8 \\
\hline \multicolumn{11}{|l|}{ Religion } \\
\hline Christianity & $\begin{array}{l}1019 \\
(72.6)\end{array}$ & 41.5 & 37.0 & 39.9 & 34.8 & 44.1 & 56.6 & 37.4 & 40.6 & 42.9 \\
\hline Islam & $329(23.4)$ & 34.7 & 30.0 & 31.6 & 38.2 & 32.1 & 87.5 & 30.0 & 30.9 & 44.2 \\
\hline $\begin{array}{l}\text { Traditional/ } \\
\text { no religion }\end{array}$ & $56(4.0)$ & 25.0 & 25.9 & 8.3 & 40.0 & 28.6 & - & 24.1 & 33.3 & 20.0 \\
\hline \multicolumn{11}{|c|}{ Timing to antenatal care booking } \\
\hline $\begin{array}{l}\text { Late (after } \\
\text { Ist } \\
\text { trimester) }\end{array}$ & $457(33.5)$ & 19.7 & 15.0 & 20.6 & 19.1 & 23.1 & 31.3 & 15.8 & 13.0 & 24.1 \\
\hline $\begin{array}{l}\text { Early } \\
\text { (within Ist } \\
\text { trimester) }\end{array}$ & $905(66.5)$ & 50.4 & 47.7 & 43.9 & 45.9 & 54.1 & 67.2 & 46.0 & 50.3 & 52.2 \\
\hline \multicolumn{11}{|c|}{ Health insurance coverage } \\
\hline $\begin{array}{l}\text { Not } \\
\text { covered }\end{array}$ & 489 (37.6) & 39.3 & 33.1 & 44.1 & 31.6 & 40.2 & 58.5 & 35.6 & 36.4 & 42.2 \\
\hline Covered & $811(62.4)$ & 40.7 & 36.7 & 34.4 & 39.6 & 41.5 & 61.4 & 32.8 & 43.1 & 42.9 \\
\hline \multicolumn{11}{|c|}{ Household headship } \\
\hline Male & $\begin{array}{l}1010 \\
(71.9)\end{array}$ & 39.1 & 35.1 & 34.0 & 35.8 & 44.5 & 59.6 & 32.1 & 38.3 & 43.4 \\
\hline Female & $394(28.1)$ & 39.6 & 31.0 & 43.1 & 35.7 & 37.8 & 59.7 & 37.3 & 35.4 & 41.1 \\
\hline \multicolumn{11}{|c|}{ Preceding birth interval } \\
\hline First born & $708(50.4)$ & 41.5 & 35.6 & 39.3 & 37.7 & 43.8 & 59.8 & 39.3 & 37.8 & 43.2 \\
\hline$<2$ years & $116(8.3)$ & 28.5 & 30.0 & 36.0 & 14.3 & 22.2 & 46.2 & 30.8 & 29.0 & 27.1 \\
\hline $2-3$ years & $474(33.8)$ & 38.8 & 33.0 & 33.3 & 34.9 & 47.9 & 66.0 & 28.3 & 38.7 & 47.1 \\
\hline $4+$ years & $106(7.6)$ & 37.7 & 34.4 & 29.2 & 47.6 & 40.0 & 44.4 & 34.5 & 42.9 & 36.7 \\
\hline \multicolumn{11}{|l|}{ Parity } \\
\hline $\mathrm{I}-2$ & $684(48.7)$ & 41.1 & 36.6 & 33.6 & 40.5 & 42.3 & 62.1 & 27.8 & 38.1 & 43.7 \\
\hline $3-4$ & $432(30.8)$ & 36.1 & 30.2 & 34.9 & 27.6 & 40.3 & 56.1 & 32.2 & 34.3 & 39.3 \\
\hline $5+$ & $288(20.5)$ & 39.6 & 33.9 & 43.8 & 35.9 & 46.3 & 58.8 & 36.3 & 41.8 & 44.4 \\
\hline
\end{tabular}

(Continued) 
Table I (Continued).

\begin{tabular}{|c|c|c|c|c|c|c|c|c|c|c|}
\hline \multirow[t]{3}{*}{ Variable } & \multirow[t]{3}{*}{ n (\%) } & \multirow{3}{*}{$\begin{array}{l}\text { Eight or } \\
\text { More } \\
\text { ANC } \\
\text { Contacts, } \\
\%\end{array}$} & \multicolumn{8}{|c|}{ Eight or More Antenatal Care Contacts } \\
\hline & & & \multicolumn{5}{|c|}{ Household Wealth Quintile } & \multicolumn{3}{|c|}{ Mothers' Educational Attainment } \\
\hline & & & $\begin{array}{l}\text { Lowest } \\
\text { (Poorest) }\end{array}$ & $\begin{array}{l}\text { Second } \\
\text { Level }\end{array}$ & Middle & $\begin{array}{l}\text { Fourth } \\
\text { Level }\end{array}$ & $\begin{array}{l}\text { Highest } \\
\text { (Richest) }\end{array}$ & $\begin{array}{l}\text { No } \\
\text { Education }\end{array}$ & Primary & $\begin{array}{l}\text { Secondary } \\
\text { or Higher }\end{array}$ \\
\hline \multicolumn{11}{|l|}{ Region } \\
\hline Western & $134(9.5)$ & 61.2 & 55.6 & 73.1 & 52.2 & 58.3 & 68.4 & 55.6 & 62.5 & 62.0 \\
\hline Central & $139(9.9)$ & 28.8 & 15.8 & 44.4 & 22.6 & 21.4 & 45.0 & 57.1 & 37.0 & 24.8 \\
\hline Greater & I I8 (8.4) & 56.8 & 36.4 & 50.0 & 45.8 & 59.0 & 70.6 & 33.3 & 35.0 & 63.0 \\
\hline Accra & & & & & & & & & & \\
\hline Volta & $121(8.6)$ & 23.1 & 8.3 & 20.7 & 15.6 & 26.1 & 69.2 & 10.0 & 24.3 & 26.6 \\
\hline Eastern & $107(7.6)$ & 35.5 & 11.8 & 29.4 & 31.3 & 46.2 & 45.2 & 31.3 & 33.3 & 37.0 \\
\hline Ashanti & $14 \mathrm{I}(10.0)$ & 44.7 & 23.8 & 33.3 & 60.6 & 43.2 & 51.7 & 46.7 & 51.6 & 42.1 \\
\hline Brong & $130(9.3)$ & 42.3 & 45.2 & 35.1 & 35.7 & 40.0 & 87.5 & 50.0 & 34.2 & 44.8 \\
\hline Ahafo & & & & & & & & & & \\
\hline Northern & $213(15.2)$ & 24.4 & 23.8 & 25.3 & 25.8 & 16.7 & - & 24.2 & 13.9 & 32.7 \\
\hline Upper East & 147 (10.5) & 64.6 & 62.9 & 84.0 & 50.0 & 50.0 & 66.7 & 61.4 & 74.3 & 61.8 \\
\hline Upper & I54 (II.0) & 20.1 & 20.3 & 13.0 & 25.0 & 22.2 & 75.0 & 20.0 & 19.4 & 20.7 \\
\hline West & & & & & & & & & & \\
\hline \multicolumn{11}{|l|}{ Ethnicity } \\
\hline Akan & 469 (33.4) & 45.0 & 33.3 & 50.0 & 41.6 & 44.3 & 53.6 & 60.7 & 50.8 & 42.9 \\
\hline $\mathrm{Ga} /$ & $67(4.8)$ & 40.3 & 30.0 & 10.0 & 35.7 & 38.5 & 65.0 & 0.0 & 26.3 & 51.2 \\
\hline Dangme & & & & & & & & & & \\
\hline Ewe & $180(12.8)$ & 32.2 & 24.2 & 34.2 & 16.3 & 41.5 & 52.0 & 23.5 & 32.1 & 33.6 \\
\hline Guan & $32(2.3)$ & 46.9 & 33.3 & 58.3 & 60.0 & 20.0 & 50.0 & 50.0 & 36.4 & 54.6 \\
\hline Mole- & $454(32.3)$ & 35.2 & 36.2 & 27.6 & 36.5 & 36.7 & 75.0 & 30.2 & 37.5 & 40.5 \\
\hline Dagbani & & & & & & & & & & \\
\hline Grusi & $60(4.3)$ & 60.0 & 68.2 & 53.3 & 50.0 & 44.4 & 100.0 & 46.7 & 62.5 & 64.9 \\
\hline Gurma & $82(5.8)$ & 19.5 & 10.4 & 25.0 & 18.2 & 75.0 & 66.7 & 20.0 & 17.9 & 21.4 \\
\hline Mande & $16(1.1)$ & 56.3 & 50.0 & 40.0 & 75.0 & 0.0 & 100.0 & 25.0 & 85.7 & 40.0 \\
\hline Other & $44(3.1)$ & 43.2 & 45.0 & 33.3 & 33.3 & 33.3 & 100.0 & 53.3 & 16.7 & 52.9 \\
\hline $\begin{array}{l}\text { Total } \\
\text { estimates }\end{array}$ & 1404 & 41.9 & 34.0 & 36.1 & 35.8 & 42.4 & 59.6 & 33.0 & 37.7 & 42.6 \\
\hline
\end{tabular}

pay premiums to register for NHIS before they can have access to comprehensive maternal health care. ${ }^{27}$

Another factor that could be attributed to the improved eight or more ANC contacts as observed among the surveyed Ghanian women as compared with other subSaharan African countries, could be the Communitybased Health Planning and Services programme (CHPS). This programme sought to provide rural and deprived communities easy access to healthcare services in health facilities. $^{29,50,51}$ The CHPS have been adjured to be a significant intervention in the assistance to providing ANC services and uncomplicated vaginal deliveries in rural communities. ${ }^{52}$ Though the prevalence is higher than other sub-Saharan African countries, sustaining and improving on this will require that improved infrastructures should be on ground and closer to women especially in the rural communities, where many women do not access health care services due to distance to health facility.

The focus of this study was towards the impact of socioeconomic status on the compliance of the WHO directive for at least eight ANC contacts. We determined the prevalence of eight or more ANC contacts among various household wealth status of the women. The results showed a progressive increase in eight or more ANC contacts with a trained health care provider from the poorest households to the richest households. The poorest, poorer, middle, richer and richest households had 


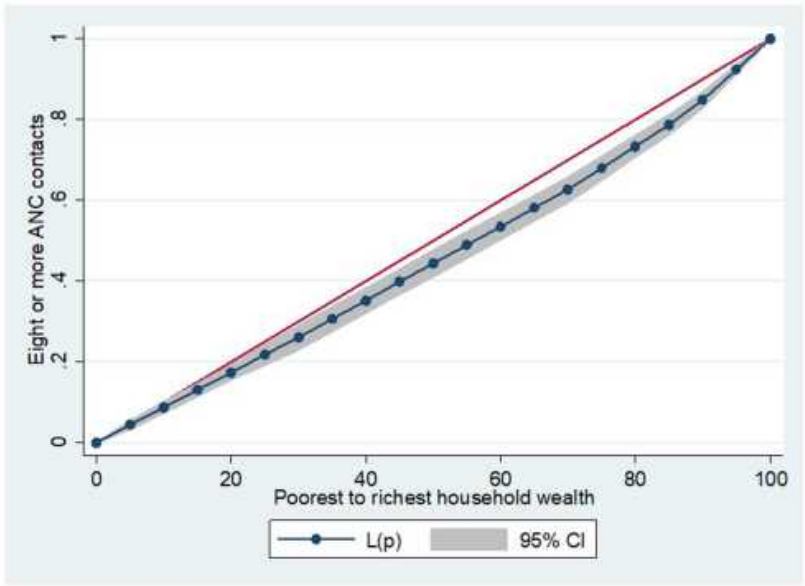

Figure I Lorenz curve for eight or more ANC contacts by household wealth.

prevalence of $34.0 \%, 36.1 \%, 35.8 \%, 42.4 \%$ and $59.6 \%$, respectively. The residential status also showed inequality in favour of the richest households. The rural richest had higher contacts $(56.0 \%)$ than the rural poorest $(34.8 \%)$. We observed socioeconomic inequality in eight or more ANC contacts during the period of pregnancy, in timing to ANC booking, health insurance coverage and household headship. These showed that household wealth played a significant role in the attainment of the WHO recommended eight or more ANC contacts among Ghanian women. It may also imply that though there is policy in Ghana that allow free maternal and child health care, ${ }^{27}$ women may still be having barriers for maternal health services. Another reason may be the fact that often, poor members of the society live in rural areas where access to health facility is difficult or non-existent. On the other

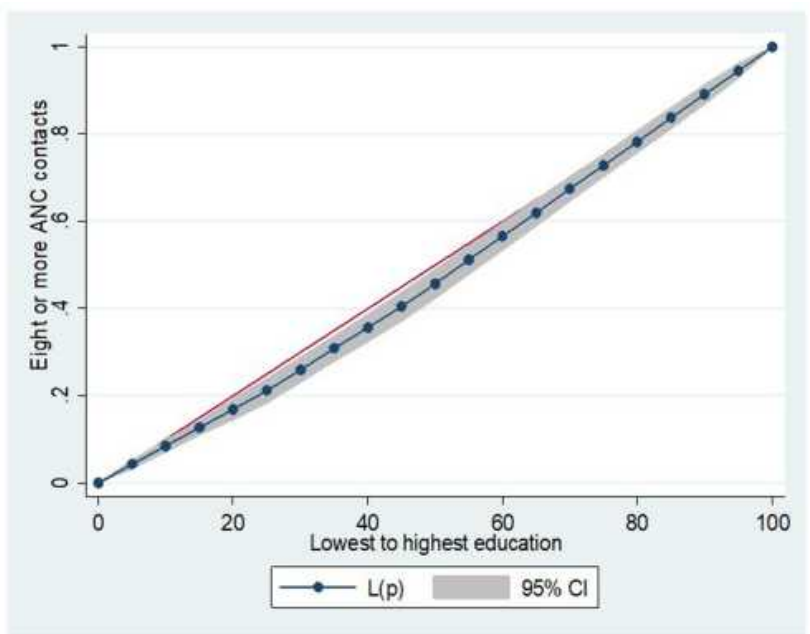

Figure $\mathbf{2}$ Lorenz curve for eight or more ANC contacts by women's education. hand, where the poor live in the cities or urban areas, they often live in the slum or poor neighbourhoods, where good infrastructures such as hospitals and schools are often unavailable or in poor state. These urban-poor women may not be privileged to access good health care. The pro-rich and pro-educated eight or more ANC contacts were observed across certain levels of women's age, religion, parity, preceding birth interval, region and ethnicity amongst others.

Furthermore, this study also found mothers' educational attainment to influence eight or more ANC contacts among Ghanian women. Those with secondary or higher education, irrespective of age, residence, timing to ANC booking, health insurance coverage and parity, had greater uptake of eight or more ANC contacts. Over the years, it has been argued that socioeconomic inequalities leading to out-of-pocket expenditure, poor access to well-equipped and functional health facilities, lack of women's enlightenment and poor or lack of decision-making power are barriers to maternal healthcare utilization. ${ }^{53-56}$ These observations are in agreement with many other reports on the analysis of socioeconomic inequalities, where women with higher educational levels and those from rich households had greater uptake for maternal health care services when compared to the less educated and disadvantaged. ${ }^{27,46,47,57-59}$

Based on the results from Lorenz curve, it is observed that there are household wealth and women's education inequalities for eight or more ANC contacts among reproductive age women in Ghana. The rich neighborhood is commonly where the members of richest class, educated, and the affluent members of a given society dwell and hence influence availability of healthcare services. The level of educational attainment is in correlation with having eight or more ANC contacts. Education is one of the major contributors to enlightenment and enhances exposure to health educational materials. Having at least secondary level of education can promote early booking for ANC and completing at least 8 ANC contacts as recommended. Studies from Nigeria, ${ }^{4,57}$ Benin, ${ }^{47,60}$ North Eastern Ethiopia ${ }^{58}$ Ghana $^{29}$ and in the rural settings of Malawi $^{61}$ have reported that educational attainment has positive influence on optimal utilization of maternal health care services. These showed the importance of educating the girl-child as it can empower her to obtain her reproductive health needs. Education or enlightenment is a factor that has shown to be a protective and an enhancer for women's utilization of maternal and child health care 
Table 2 Household Wealth and Educational Attainment Inequalities in Early Initiation of Breastfeeding

\begin{tabular}{|c|c|c|c|c|}
\hline \multirow[t]{2}{*}{ Variable } & \multicolumn{2}{|l|}{ Household Wealth Quintile } & \multicolumn{2}{|l|}{ Mothers' Education } \\
\hline & Concentration Index (SE) & $\mathbf{P}$ & Concentration Index (SE) & $\mathbf{P}$ \\
\hline Age & & $0.016 *$ & & 0.370 \\
\hline $15-24$ & $0.024(0.037)$ & & $0.040(0.033)$ & \\
\hline $25-34$ & $0.138(0.026)^{*}$ & & $0.089(0.024)^{*}$ & \\
\hline $35+$ & $0.044(0.036)$ & & $0.043(0.034)$ & \\
\hline Residential status & & 0.220 & & 0.461 \\
\hline Urban & $0.114(0.027)^{*}$ & & $0.058(0.023)^{*}$ & \\
\hline Rural & $0.067(0.025)^{*}$ & & $0.031(0.024)$ & \\
\hline Religion & & 0.662 & & 0.189 \\
\hline Christianity & $0.07 \mathrm{I}(0.02 \mathrm{I})^{*}$ & & $0.023(0.018)$ & \\
\hline Islam & $0.108(0.04 I)^{*}$ & & $0.09 \mathrm{I}(0.04 \mathrm{I})^{*}$ & \\
\hline Traditional/no religion & $0.042(0.127)$ & & $-0.013(0.124)$ & \\
\hline Timing to antenatal care booking & & 0.281 & & $0.039 *$ \\
\hline Late (after Ist trimester) & $0.111(0.053)^{*}$ & & $0.112(0.049)^{*}$ & \\
\hline Early (within Ist trimester) & $0.062(0.018)^{*}$ & & $0.024(0.017)$ & \\
\hline Health insurance coverage & & 0.806 & & 0.950 \\
\hline Not covered & $0.075(0.03 \mathrm{I})^{*}$ & & $0.040(0.029)$ & \\
\hline Covered & $0.084(0.024)^{*}$ & & $0.043(0.022)$ & \\
\hline Household headship & & 0.782 & & 0.337 \\
\hline Male & $0.085(0.022)^{*}$ & & $0.064(0.021)^{*}$ & \\
\hline Female & $0.097(0.035)^{*}$ & & $0.025(0.029)$ & \\
\hline Preceding birth interval & & 0.410 & & $0.046 *$ \\
\hline First born & $0.084(0.025)^{*}$ & & $0.025(0.022)$ & \\
\hline$<2$ years & $-0.003(0.084)$ & & $-0.027(0.078)$ & \\
\hline $2-3$ years & $0.116(0.032)^{*}$ & & $0.112(0.031)^{*}$ & \\
\hline $4+$ years & $0.062(0.070)$ & & $0.004(0.067)$ & \\
\hline Parity & & 0.909 & & 0.990 \\
\hline $1-2$ & $0.091(0.025)^{*}$ & & $0.05 \mathrm{I}(0.02 \mathrm{I})^{*}$ & \\
\hline $3-4$ & $0.101(0.036)^{*}$ & & $0.046(0.034)$ & \\
\hline $5+$ & $0.077(0.040)$ & & $0.046(0.039)$ & \\
\hline Region & & $0.034 *$ & & 0.611 \\
\hline Western & $0.003(0.039)$ & & $0.011(0.033)$ & \\
\hline Central & $0.040(0.075)$ & & $-0.112(0.057)$ & \\
\hline Greater Accra & $0.106(0.044)^{*}$ & & $0.086(0.033)^{*}$ & \\
\hline Volta & $0.304(0.089)^{*}$ & & $0.110(0.087)$ & \\
\hline Eastern & $0.176(0.072)^{*}$ & & $0.030(0.062)$ & \\
\hline Ashanti & $0.089(0.053)$ & & $-0.036(0.045)$ & \\
\hline Brong Ahafo & $0.031(0.057)$ & & $0.010(0.054)$ & \\
\hline Northern & $0.009(0.064)$ & & $0.035(0.06 \mathrm{I})$ & \\
\hline Upper East & $0.004(0.029)$ & & $-0.006(0.033)$ & \\
\hline Upper West & $0.057(0.085)$ & & $0.008(0.087)$ & \\
\hline Ethnicity & & $0.011 *$ & & 0.325 \\
\hline Akan & $0.047(0.029)$ & & $-0.040(0.020) *$ & \\
\hline Ga/Dangme & $0.226(0.080)^{*}$ & & $0.187(0.070)^{*}$ & \\
\hline Ewe & $0.134(0.06 \mathrm{I})^{*}$ & & $0.034(0.054)$ & \\
\hline
\end{tabular}

(Continued) 
Table 2 (Continued).

\begin{tabular}{|l|l|l|l|}
\hline \multirow{2}{*}{ Variable } & \multicolumn{2}{l|}{ Household Wealth Quintile } & \multicolumn{2}{l|}{ Mothers' Education } \\
\cline { 2 - 4 } & Concentration Index (SE) & P & \multicolumn{2}{l|}{ Concentration Index (SE) } \\
\hline Guan & $-0.013(0.108)$ & & $0.025(0.106)$ \\
Mole-Dagbani & $0.019(0.034)$ & $0.070(0.034)^{*}$ \\
Grusi & $-0.029(0.059)$ & $0.059(0.053)$ \\
Gurma & $0.334(0.110)^{*}$ & $-0.002(0.120)$ \\
Mande & $0.111(0.128)$ & $0.028(0.127)$ \\
Other & $0.031(0.096)$ & $0.008(0.096)$ \\
Total estimates & $0.089(0.019)^{*}$ & $0.053(0.017)^{*}$ \\
\hline
\end{tabular}

Notes: *Significant at $p<0.05 . p=$ comparing concentration indices across the levels of a variable.

Abbreviation: SE, standard error.

services and in making decisions concerning their reproductive health including eight or more ANC contacts. ${ }^{62,63}$

In addition, educated women could be assumed to have good knowledge of optimal benefits of adequate ANC contacts during the period of pregnancy ${ }^{64}$ One of the effective ways to empower women is by giving them education. It has the capacity to provide them with the ability to make right choices concerning the use of modern health care services. ${ }^{47,63}$ Wealth could also be a mechanism of women's empowerment. The findings from this study revealed higher uptake of eight or more ANC contacts among women of high socioeconomic status throughout selected women's characteristics. To eliminate inequality in access and use of healthcare services, especially among the disadvantaged and uneducated women, universal access to uptake maternal healthcare services must be the priority of governments at national and sub-national levels.

\section{Strength and Limitations}

The use of nationally representative high-quality data from household survey was a major strength of this study. Also, appropriate statistical adjustments for the survey designs make the results of this study dependable. Nonetheless, a major limitation of this paper is the potential for recall bias which might lead to an over-, or under-estimation of eight or more ANC contacts. GMIS also does not collect household income or expenditure data, which are the conventional metrics used for wealth calculation. The assetbased wealth index used here is merely a household economic status proxy indicator and does not always yield results that are accurate to those obtained from direct income and expenditure measurements where such data is available or can be accurately collected.

\section{Conclusion}

While Ghana has made progress towards the recognition of eight or more ANC contacts by the WHO, there are still a lot of socio-economic disparities across women's features and overall sample. The findings from this study show that the new recommended number of eight and more ANC contacts is still far from being achieved by the government. In order for the nation to increase access to recommended treatment during pregnancy and for a healthy pregnancy experience to improve maternal health and birth outcomes, interventions that resolve health access disparities must be prioritized. Every effort must be made to enhance the health care services available, as well as to enact policies that can increase free access to maternal and child health care systems, and optimize eight or more ANC contacts among the poor and uneducated women.

\section{Abbreviations}

ANC, Antenatal Care; CHPS, Community-based Health Planning and Services; CI, Confidence Interval; Conc., Concentration; EAs, Enumeration Areas; GMIS, Ghana Malaria Indicator Survey; ICF, Inner City Fund; NHIS, National Health Insurance Scheme; PCA, Principal Components Analysis; SDGs, Sustainable Development Goals; SE, Standard Error; TX, Texas; UHC, Universal Health Coverage; USA, United States of America; WHO, World Health Organization.

\section{Data Sharing Statement}

Data for this study were sourced and available here: http:// dhsprogram.com/data/available-datasets.cfm. 


\section{Ethics Approval and Consent to Participate}

This study is a secondary data analysis of the GMIS which is publicly available, and approval was granted for its use. Written consent was obtained from mothers/caregivers and data were recorded anonymously at the time of data collection during the GMIS 2019.

\section{Acknowledgment}

The authors appreciate the Malaria Indicator Survey (MIS) for the approval and access to the original data.

\section{Author Contributions}

All authors made substantial contributions to conception and design, acquisition of data, or analysis and interpretation of data; took part in drafting the article or revising it critically for important intellectual content; agreed to submit to the current journal; gave final approval of the version to be published; and agree to be accountable for all aspects of the work.

\section{Funding}

This research received no grant from any funding agency in the public, commercial or not-for-profit sectors.

\section{Disclosure}

The authors report no conflicts of interest for this work and declare that the research was conducted in the absence of any commercial or financial relationships that could be construed as a potential conflict of interest.

\section{References}

1. Okedo-Alex IN, Akamike IC, Ezeanosike OB, Uneke CJ. Determinants of antenatal care utilisation in sub-Saharan Africa: a systematic review. BMJ Open. 2019;9:e031890. doi:10.1136/bmjopen-2019-031890

2. Alkema L, Chou D, Hogan D, et al. Global, regional, and national levels and trends in maternal mortality between 1990 and 2015, with scenario-based projections to 2030: a systematic analysis by the UN Maternal Mortality Estimation Inter-Agency Group. Lancet. 2016;387:462-474. doi:10.1016/S0140-6736(15)00838-7

3. World Health Organization, UNICEF, United Nations, Department of Economic and Social Affairs, Population Division, World Bank. Trends in maternal mortality: 1990 to 2015: estimates by WHO, UNICEF, UNFPA, World Bank Group and the United Nations Population Division; 2015. Available from: http://www.who.int/repro ductivehealth/publications/monitoring/maternal-mortality-2015/en/. Accessed March 17, 2021.

4. Adeyanju O, Tubeuf S, Ensor T. Socio-economic inequalities in access to maternal and child healthcare in Nigeria: changes over time and decomposition analysis. Health Policy Plan. 2017;32:1111-1118. doi:10.1093/heapol/czx049
5. Barros AJ, Ronsmans C, Axelson H, et al. Equity in maternal, newborn, and child health interventions in Countdown to 2015: a retrospective review of survey data from 54 countries. Lancet. 2012;379:1225-1233. doi:10.1016/S0140-6736(12)60113-5

6. Zere E, Oluwole D, Kirigia JM, Mwikisa CN, Mbeeli T. Inequities in skilled attendance at birth in Namibia: a decomposition analysis. BMC Pregnancy Childbirth. 2011;11:34. doi:10.1186/1471-2393-11-34

7. Eshetu E, Woldesenbet S. Are there particular social determinants of health for the world's poorest countries? Afr Health Sci. 2011;11:108-115.

8. Lozano R, Fullman N, Mumford JE, et al. Measuring universal health coverage based on an index of effective coverage of health services in 204 countries and territories, 1990-2019: a systematic analysis for the Global Burden of Disease Study 2019. Lancet. 2020;8: S0140673620307509. doi:10.1016/S0140-6736(20)30750-9

9. Arsenault C, Jordan K, Lee D, et al. Equity in antenatal care quality: an analysis of 91 national household surveys. Lancet Glob Health. 2018;6:e1186-e1195. doi:10.1016/S2214-109X(18)30389-9

10. Alam N, Hajizadeh M, Dumont A, Fournier P. Inequalities in maternal health care utilization in Sub-Saharan African countries: a multiyear and multi-country analysis. PLoS One. 2015;10: e0120922. doi:10.1371/journal.pone.0120922

11. Pulok MH, Uddin J, Enemark U, Hossin MZ. Socioeconomic inequality in maternal healthcare: an analysis of regional variation in Bangladesh. Health Place. 2018;52:205-214. doi:10.1016/j. healthplace.2018.06.004

12. Goli S, Nawal D, Rammohan A, Sekher TV, Singh D. Decomposing the socioeconomic inequality in utilization of maternal health care services in selected countries of south Asia and sub-Saharan Africa. J Biosoc Sci. 2018;50:749-769. doi:10.1017/ S0021932017000530

13. Rosa W, editor. Transforming Our World: The 2030 Agenda for Sustainable Development. A New Era in Global Health. New York, NY: Springer Publishing Company; 2017. doi:10.1891/ 9780826190123.ap02.

14. Kieny MP, Bekedam H, Dovlo D, et al. Strengthening health systems for universal health coverage and sustainable development. Bull World Health Organ. 2017;95:537-539. doi:10.2471/BLT.16.187476

15. Bonfrer I, van de Poel E, Grimm M, Van Doorslaer E. Does the distribution of healthcare utilization match needs in Africa? Health Policy Plan. 2014;29:921-937. doi:10.1093/heapol/czt074

16. World Health Organization. WHO Recommendations on Antenatal Care for a Positive Pregnancy Experience. Geneva: World Health Organization; 2016.

17. UNICEF. Antenatal care. UNICEF DATA [Internet]; 2021. Available from: https://data.unicef.org/topic/maternal-health/antenatal-care/. Accessed March 17, 2021.

18. Kuhnt J, Vollmer S. Antenatal care services and its implications for vital and health outcomes of children: evidence from 193 surveys in 69 low-income and middle-income countries. BMJ Open. 2017;7: e017122. doi:10.1136/bmjopen-2017-017122

19. Nimi T, Fraga S, Costa D, Campos P, Barros H. Prenatal care and pregnancy outcomes: a cross-sectional study in Luanda, Angola. Int $J$ Gynecol Obstet. 2016;135:S72-S78. doi:10.1016/j. ijgo.2016.08.013

20. Afulani PA. Determinants of stillbirths in Ghana: does quality of antenatal care matter? BMC Pregnancy Childbirth. 2016;16:132. doi:10.1186/s12884-016-0925-9

21. Ntambue AM, Malonga FK, Dramlx-Wilmet M, Donnen P. Determinants of maternal health services utilization in urban settings of the Democratic Republic of Congo - a Case study of Lubumbashi City. BMC Pregnancy Childbirth. 2012;12.

22. Gitonga E, Muiruri F. Determinants of health facility delivery among women in Tharaka Nithi county, Kenya. Pan Afr Med J. 2016;25 (Suppl 2). doi:10.11604/pamj.supp.2016.25.2.10273 
23. Dahiru T, Oche OM. Determinants of antenatal care, institutional delivery and postnatal care services utilization in Nigeria. Pan Afr Med J. 2015;21. doi:10.11604/pamj.2015.21.321.6527.

24. De Allegri M, Ridde V, Louis VR, et al. Determinants of utilisation of maternal care services after the reduction of user fees: a case study from rural Burkina Faso. Health Policy (New York). 2011;99:210-218. doi:10.1016/j.healthpol.2010.10.010

25. Adjiwanou V, LeGrand T. Does antenatal care matter in the use of skilled birth attendance in rural Africa: a multi-country analysis. Soc Sci Med. 2013;86:26-34. doi:10.1016/j.socscimed.2013.02.047

26. Tekelab T, Yadecha B, Melka AS. Antenatal care and women's decision making power as determinants of institutional delivery in rural area of Western Ethiopia. BMC Res Notes. 2015;8:769. doi:10.1186/s13104-015-1708-5

27. Novignon J, Ofori B, Tabiri KG, Pulok MH. Socioeconomic inequalities in maternal health care utilization in Ghana. Int $J$ Equity Health. 2019;18:141. doi:10.1186/s12939-019-1043-x

28. Blanchet NJ, Fink G, Osei-Akoto I. The effect of Ghana's national health insurance scheme on health care utilisation. Ghana Med J. 2012;46:76-84.

29. Nyonator FK, Awoonor-Williams JK, Phillips JF, Jones TC, Miller RA. The Ghana community-based health planning and services initiative for scaling up service delivery innovation. Health Policy Plan. 2005;20:25-34. doi:10.1093/heapol/czi003

30. Okoroh J, Essoun S, Seddoh A, et al. Evaluating the impact of the national health insurance scheme of Ghana on out of pocket expenditures: a systematic review. BMC Health Serv Res. 2018;18:426. doi:10.1186/s12913-018-3249-9

31. Adewuyi EO, Auta A, Khanal V, et al. Prevalence and factors associated with underutilization of antenatal care services in Nigeria: a comparative study of rural and urban residences based on the 2013 Nigeria demographic and health survey. PLoS One. 2018;13:e0197324. doi:10.1371/journal.pone.0197324

32. Fagbamigbe AF, Idemudia ES. Wealth and antenatal care utilization in Nigeria: policy implications. Health Care Women Int. 2017;38:17-37. doi:10.1080/07399332.2016.1225743

33. Pallikadavath S, Foss M, Stones RW. Antenatal care: provision and inequality in rural north India. Soc Sci Med. 2004;59:1147-1158. doi:10.1016/j.socscimed.2003.11.045

34. Joshi C, Torvaldsen S, Hodgson R, Hayen A. Factors associated with the use and quality of antenatal care in Nepal: a population-based study using the demographic and health survey data. BMC Pregnancy Childbirth. 2014;14:94. doi:10.1186/1471-2393-14-94

35. Navaneetham K, Dharmalingam A. Utilization of maternal health care services in Southern India. Soc Sci Med. 2002;55:1849-1869. doi:10.1016/S0277-9536(01)00313-6

36. Ghana Statistical Service (GSS) and ICF. Ghana malaria indicator survey 2019; 2020. Accra, Ghana, and Rockville, Maryland, USA: GSS and ICF. Available from: https://dhsprogram.com/pubs/pdf/ MIS35/MIS35.pdf. Accessed March 17, 2021.

37. Tunçalp Ö, Pena-Rosas J, Lawrie T, et al. WHO recommendations on antenatal care for a positive pregnancy experience-going beyond survival. BJOG Int $J$ Obstet Gynaecol. 2017;124:860-862. doi:10.1111/1471-0528.14599

38. de Masi S, Bucagu M, Tunçalp Ö, et al. Integrated person-centered health care for all women during pregnancy: implementing World Health Organization recommendations on antenatal care for a positive pregnancy experience. Glob Health Sci Pract. 2017;5:197-201. doi:10.9745/GHSP-D-17-00141

39. Szklarska A, Jankowska EA. Independent effects of social position and parity on body mass index among Polish adult women. J Biosoc Sci. 2003;35:575-583. doi:10.1017/S002193200300600X

40. Walters S, Suhrcke M. Socioeconomic Inequalities in Health and Health Care Access in Central and Eastern Europe and the CIS. WHO European Office for Investment for Health and Development; 2005:50.
41. Bado AR, Sathiya Susuman A. Women's education and health inequalities in under-five mortality in selected Sub-Saharan African countries, 1990-2015. PLoS One. 2016;11:e0159186. doi:10.1371/ journal.pone.0159186

42. Rutstein SO, Staveteig S. Making the Demographic and Health Surveys Wealth Index Comparable; DHS Methodological Reports No. 9. Rockville, Maryland, USA: ICF International; 2014.

43. Uthman OA. Using extended concentration and achievement indices to study socioeconomic inequality in chronic childhood malnutrition: the case of Nigeria. Int J Equity Health. 2009;8:22. doi:10.1186/ 1475-9276-8-22

44. Ekholuenetale M, Tudeme G, Onikan A, Ekholuenetale CE. Socioeconomic inequalities in hidden hunger, undernutrition, and overweight among under-five children in 35 sub-Saharan Africa countries. J Egypt Public Health Assoc. 2020;95:9. doi:10.1186/ s42506-019-0034-5

45. WHO Reproductive Health Library. WHO Recommendation on Antenatal Care Contact Schedules. WHO Reproductive Health Library Geneva World Health Organization; 2018. 7.

46. Ekholuenetale M, Benebo FO, Idebolo AF. Individual-, household-, and community-level factors associated with eight or more antenatal care contacts in Nigeria: evidence from demographic and health survey. PLoS One. 2020;15:e0239855. doi:10.1371/journal. pone. 0239855

47. Ekholuenetale M, Nzoputam CI, Barrow A, Onikan A. Women's enlightenment and early antenatal care initiation are determining factors for the use of eight or more antenatal visits in Benin: further analysis of the Demographic and Health Survey. J Egypt Public Health Assoc. 2020;95:13. doi:10.1186/s42506-020-00041-2

48. Knoema. Ghana maternal mortality ratio, 1960-2020 - knoema.com; 2021. Available from: https://knoema.com//atlas/Ghana/Maternalmortality-ratio. Accessed March 17, 2021.

49. Wang W, Temsah G, Mallick L. The impact of health insurance on maternal health care utilization: evidence from Ghana, Indonesia and Rwanda. Health Policy Plan. 2016;czw135. doi:10.1093/heapol/ czw135

50. Awoonor-Williams JK, Bawah AA, Nyonator FK, et al. The Ghana essential health interventions program: a plausibility trial of the impact of health systems strengthening on maternal \& child survival. BMC Health Serv Res. 2013;13:S3. doi:10.1186/1472-6963-13-S2-S3

51. Nwameme AU, Tabong PT-N, Adongo PB. Implementing community-based health planning and services in impoverished urban communities: health workers' perspective. BMC Health Serv Res. 2018;18:186. doi:10.1186/s12913-018-3005-1

52. Johnson FA, Frempong-Ainguah F, Matthews Z, et al. Evaluating the impact of the community-based health planning and services initiative on uptake of skilled birth care in Ghana. PLoS One. 2015;10. doi:10.1371/journal.pone.0120556

53. Yaya S, Bishwajit G, Ekholuenetale M, Shah V, Kadio B, Udenigwe $\mathrm{O}$. Timing and adequate attendance of antenatal care visits among women in Ethiopia. PLoS One. 2017;12:e0184934. doi:10.1371/journal.pone.0184934

54. Gebremeskel F, Dibaba Y, Admassu B. Timing of first antenatal care attendance and associated factors among pregnant women in Arba Minch Town and Arba Minch District, Gamo Gofa Zone, South Ethiopia. J Environ Public Health. 2015;2015:1-7. doi:10.1155/ 2015/971506

55. Gudayu TW, Woldeyohannes SM, Abdo AA. Timing and factors associated with first antenatal care booking among pregnant mothers in Gondar Town; North West Ethiopia. BMC Pregnancy Childbirth. 2014;14:287. doi:10.1186/1471-2393-14-287

56. Tolefac PN, Halle-Ekane GE, Agbor VN, Sama CB, Ngwasiri C, Tebeu PM. Why do pregnant women present late for their first antenatal care consultation in Cameroon? Matern Health Neonatol Perinatol. 2017;3:29. doi:10.1186/s40748-017-0067-8 
57. Nwosu CO, Ataguba JE. Socioeconomic inequalities in maternal health service utilisation: a case of antenatal care in Nigeria using a decomposition approach. BMC Public Health. 2019;19:1493. doi:10.1186/s12889-019-7840-8

58. Shibre G, Mekonnen W. Socio-economic inequalities in ANC attendance among mothers who gave birth in the past 12 months in Debre Brehan town and surrounding rural areas, North East Ethiopia: a community-based survey. Reprod Health. 2019;16:99. doi:10.1186/ s12978-019-0768-8

59. Dixon J, Tenkorang EY, Luginaah IN, Kuuire VZ, Boateng GO. National health insurance scheme enrolment and antenatal care among women in Ghana: is there any relationship? Trop Med Int Health. 2014;19:98-106. doi:10.1111/tmi.12223

60. Dansou J, Adekunle A, Arowojolu A. Factors associated with antenatal care services utilisation patterns amongst reproductive age women in Benin Republic: an analysis of 2011/2012 benin republic's demographic and health survey data. Niger Postgrad Med J. 2017;24:67. doi:10.4103/npmj.npmj_16_17
61. Zamawe COF, Banda M, Dube AN. The impact of a community driven mass media campaign on the utilisation of maternal health care services in rural Malawi. BMC Pregnancy Childbirth. 2016;16:21. doi:10.1186/s12884-016-0816-0

62. Aziz Ali S, Ahmed Dero A, Aziz Ali S, Bano Ali G. Factors affecting the utilization of antenatal care among pregnant women: a literature review. J Pregnancy Neonatal Med. 2018;02. doi:10.35841/neonatalmedicine.2.2.41-45.

63. Djoukou Olga Denise K, Mélèdje Marie-Dorothée K, Yacé MarieLaurette A, et al. Factors associated with maternal health service utilization in Cote d'Ivoire: analysis of the 2011 Ivorian Demographic and Health Survey. Sci J Public Health. 2019;7:115. doi:10.11648/j.sjph.20190704.12

64. Awasthi MS, Awasthi KR, Thapa HS, Saud B, Pradhan S, Khatry RA. Utilization of antenatal care services in dalit communities in Gorkha, Nepal: a Cross-Sectional Study. $J$ Pregnancy. 2018;2018:1-8. doi:10.1155/2018/3467308

\section{Publish your work in this journal}

The International Journal of Women's Health is an international, peerreviewed open-access journal publishing original research, reports, editorials, reviews and commentaries on all aspects of women's healthcare including gynecology, obstetrics, and breast cancer. The manuscript management system is completely online and includes a very quick and fair peer-review system, which is all easy to use. Visit http://www.dovepress.com/testimonials.php to read real quotes from published authors. 